\title{
Porchat sobre o argumento da loucura
}

\author{
Lívia Guimarães \\ Universidade Federal de Minas Gerais (UFMG)
}

\section{RESUMO}

Este ensaio se divide em duas partes. $\mathrm{Na}$ primeira, retorno, brevemente, aoprogresso da filosofia de Porchat, apontando algumas de suas descobertas notáveis, em artigos reunidos no "Rumo ao ceticismo", coletânea de 2007, com publicaçóes de 1969 a 2005. Meu primeiro objetivo é contextualizar "O argumento da loucura", artigo que encerra a coletânea, na obra do filósofo. $\mathrm{Na}$ segunda parte, que se inicia com uma revisão de "O argumento da loucura", proponho uma análise em que o argumento de Porchat se traduz em argumentos céticos, anticartesianos, anti ultrarracionalismos, comparandose, por exemplo, aos de Hume, mas em que o texto se apresenta também como um procedimento, prática, terapêutica, contemporânea e original. Nessa interpretação, ele se aproxima simpaticamente das filosofias nas quais Porchat reconhece um fascínio pelo que ele denomina "absoluto", acompanha-as pelas tribulaçóes que lhes são sintomáticas, e as conduz à resolução cética. Inevitáveis são as perguntas: o que pode significar esse "absoluto"? como se conduz o procedimento terapêutico? A que resultado cético porchatiano ele leva? Aqui pode, em minha hipótese, encontrar no argumento da loucura antes um modo ou tropo do ceticismo, que vem resgatar práticas filosóficas inclinadas ao sem sentido de "espaços transmundanos", trazendo-as de volta à rica variedade das experiências mundanas, que se constituem em verdadeiras filosofias, para Porchat.

\section{PALAVRAS-CHAVE}

Porchat; Argumento da Loucura; Ceticismo.

\begin{abstract}
This essay is divided into two parts. In the first, I briefly return to the progress of Porchat's philosophy, pointing to some of his remarkable discoveries in articles collected in "Towards Scepticism," a collection of 2007, with publications from 1969 to 2005. My first goal is to contextualize the article "Of the Madness Argument", the article that closes the collection, within the work of the philosopher. In the second part, which begins with a review of the Madness Argument, I propose an analysis in which Porchat's argument is translated into sceptical, anti-Cartesian, anti-ultra-rationalist arguments, comparing, for example, to Hume's, but in which the text is also presented as a procedure, practice, therapy, contemporary and original. In this interpretation, it sympathizes with the philosophies in which Porchat recognizes a fascination with what he calls "absolute", accompanies them through their symptomatic tribulations, and leads them to a sceptical resolution. I nevitable are the questions: what can this "absolute" mean? how is the therapeutic procedure conducted? to what sceptical result does it take? Here, in my hypothesis, I find in the argument of madness to consist of rather a mode or trope of scepticism, which comes to redeem philosophical practices inclined to senseless "transmundane spaces", bringing them back to the rich variety of worldly experiences which constitute true philosophies, according to Porchat.
\end{abstract}

\section{KEY WORDS}

Porchat; Madness Argument; Scepticism. 


\section{Antes do argumento da loucura}

No prefácio ao livro que leva o eloquente título "Rumo ao ceticismo", escrito em 2006, Porchat diz: "sempre entendi que é preciso filosofar em terra, que a filosofia é coisa do mundo, é artefacto produzido pelos homens, em sua busca da felicidade"1. É precisamente a esse lugar que o argumento da loucura o conduz, é aí que ele termina. Com efeito, desde "O conflito das filosofias", que introduz este volume, que se conclui com o artigo "O argumento da loucura", temos vislumbres do argumento. Já em 1968, na aula inaugural do Departamento de Filosofia da Universidade de São Paulo, ou seja, n’O conflito das filosofias”, aliando-se a Protágoras, Górgias, Sexto Empírico e ao ceticismo antigo, Porchat denuncia a "extensa galeria dos metafísicos de todos os tempos, cujo traço fundamental de união talvez possa dizer-se o comungarem, de alguma maneira, da crença grega na divindade da razáo especulativa" (Rumo ao ceticismo, doravante, RC, I4). No mesmo espírito, ele denuncia a crença desses metafísicos na "capacidade humana de obter, através da simples reflexão, conhecimentos seguros e absolutos, suscetíveis de exprimir-se num discurso que exprimisse uma como intuição divina" (RC I4). Em I968, Porchat assinala o conflito das filosofias, mas enxerga o problema do qual o argumento da loucura vai tratar: o fascínio das muitas metafísicas por algo dito "absoluto" - a se entender, explicar, dissipar.

No "Prefácio a uma filosofia", de 1975, autobiográfico, confessional, lê-se a instauração do ceticismo na atualidade, num texto que espelha, para subverter, Descartes. Num intenso e sofrido drama, Porchat vive as ilusóes e perturbacôes das escolas dogmáticas, polemiza, encontra o arremedo de diálogo (a preleção do mestre ao discípulo), e contempla a meditação solitária "no ócio dos desertos" (RC 33). Ele, em breve momento de total desencanto com a filosofia, decide abdicar dela em favor da vida comum e mergulha no mundo "com volúpia", antes de encontrar, nesse mergulho e na vida comum, ao modo do pirrônico, assim, por acaso, a verdadeira filosofia ( $\left.\mathrm{RC}_{3} 6\right)$ - não dogmática, do fenômeno, do que aparece.

É o mesmo Porchat que, ensaiando situaçóes e pontos de vista, encontra-se, na simplicidade, não mais em convolutas aporias e requintada sofisticação ( $\mathrm{RC}_{39}$ ), ao mesmo tempo em que desacredita nas vãs promessas dos métodos e sistemas positivos (RC 44), em "A filosofia e a visão da comum do mundo", de I979. O artigo de I979 complementa o de 75. Aqui, interessa ao filósofo compreensão, não problematização, (RC 62), e ele se depara com e nos póe diante de um mundo de eventos, vidas corpóreas, e de sensações, emoçóes, prazeres, dores, desejos e sentimentos; do

1 Oswaldo Porchat Pereira, 2007, p. 9. Em referências futuras: RC, seguido da página. 
"nós" que toma o lugar do "eu", e desse nós que, por semelhanca, tem uma experiência e visão comum de mundo, compartilhada, intersectada, histórica. O Porchat desse ensaio, a certa altura, usa linguagem sensória e honorífica para essa filosofia "humanizada e mundanizada" (RC 57): ela é de se saborear, diz ele; chegar a ela constitui-se em uma promoção (não demoção) da filosofia (RC 53).

Nas centenas de páginas e nas décadas vividas após os artigos apontados acima — inaugurais, não tem fim o que se pode dizer da evolução da filosofia de Porchat. Mas para os modestos objetivos desse ensaio, que se limita ao argumento da loucura, talvez baste notar a recorrência de três componentes: filosofias do absoluto, terapias filosóficas, filosofias da vida comum.

Apenas a título de exemplo, no "Ceticismo e mundo exterior", de 1986, assinalo: (i) os termos fortes que Porchat escolhe para formular o impasse dogmático que leva ao dualismo, ou ao mentalismo cético, ecoando o "Prefácio", onde observa que não temos como ascender de certezas subjetivas a certezas objetivas; intuições psicológicas a intuiçóes intelectuais; conhecimentos empíricos a conhecimentos absolutos; substituir à nossa subjetividade empírica, uma subjetividade transcendental. Temos, aqui, explícitas, as pretensóes das filosofias do absoluto. Em outros escritos, posteriores, ele compatibiliza algumas das oposiçóes, ao ponto de reconciliar ceticismo, conhecimento e objetividade, por exemplo, mantendo, porém, os últimos, livres da rarefação dogmática, já que falíveis e empíricos. $\mathrm{O}$ extremo das oposiçóes, quando acontece, pode dever-se ao contexto do artigo, que se debate contra o extremo ceticismo a que se segue o extremo dogmatismo de Descartes. Ou seja, no debate, Porchat encontra-se diante da presunção de confiabilidade absoluta da razão filosofante, à qual precisa opor um contraponto equivalente.

Isso nos leva ao item (ii): a menção aos argumentos do sonho e da loucura, que se encontram no texto de Descartes, mas que remontam a Carnéades (RC IO3). Concernindo a loucura, haverá, como sabemos, a adição da instância porchatiana.

Em "Sobre o que aparece", de I99I, ressaltam, para o objetivo dessa revisão: uma espécie de diagnóstico, apontando um traço do pensamento filosófico, e mesmo do comum - a obstinação do absoluto (RC I2I); e a afirmação inequívoca de que o neopirronismo se constitui em prática filosófica terapêutica (RC I39,I44), visando, supôe-se, a cura dessa obstinação. No "Ceticismo e argumentação", de 1993, dedicado a Ezequiel de Olaso, Porchat se e nos denomina um "auditório universal” (RC I48), sob a ameaça dos fascinantes argumentos do "demônio dogmático" (RC I56). Aqui, para ele, a argumentação cética, que, a um só tempo, denuncia e desmistifica o discurso dogmático, serve-se de antinomias (RC I57). Sob seus cuidados, está o discurso e, por trás dele, a presunção e precipitação dos dogmáticos (RC I60). Assim como em artigos anteriores, Porchat faz uso de metáforas, referências e comparaçóes 
entre pensamentos passados e presentes. Como mencionei, tem de lidar com um demônio (referência óbvia a Descartes). Elege em Hume, agora, erroneamente (erro deliberado?), o representante exemplar do ceticismo moderno, negativo (como fizera, no "Sobre o que aparece", na companhia de Rorty, que via em Hume um cético mentalista, que se retrai em seu mundo interior ( $\mathrm{RC}_{\mathrm{I} 3 \mathrm{I}}$ ).

O ceticismo terapêutico antevê, mas não desenvolve o argumento da loucura precocemente. Numa tirada humorística, a fim de nos lembrar da humanidade de nossa razão, Porchat afirmaser preciso cortar as asas da ave de Minerva, pois é apenas nas asas do mito que nossas mentes saem para fora delas mesmas, verdadeiro desatino. Dogmáticos são os que tomam o mito literalmente — desatinados, eles deliram ( $\mathrm{RC}_{34}$ ).

Finda a terapia, há, decerto, outras funçóes, para o neopirronista, o que nos leva a (iii) filosofias da vida comum: no "Ceticismo e argumentação", ele é cronista (RC I44), que faz o relato metodizado e sistematizado da visa comum (RC I4I, ênfase minha, notando o vocabulário - propositado - humeano), em outras palavras, nos termos de Porchat, o cronista que relata "o que lhe aparece", o fenômeno (RC I39). Ao fazê-lo, pratica a ciência, e promove o bem-estar ( $\mathrm{RC}$ I42) e o progresso ( $\mathrm{RC}$ I44). Porchat nomeia filosofias afins à sua, na antiguidade, Carnéades, na modernidade, Hume. Nas suas palavras: são dotadas de gozo, riso e graça, feitas de sangue, suor e lágrimas (parodiando o político inglês, Winston Churchill). Como ele diz no "Prefácio", já citado acima: "Filosofamos em terra firme".

Um último exemplo, saindo do tempo do Vida comum e Ceticismo, de $1993,{ }^{2} \mathrm{e}$ ingressando no do Rumo ao Ceticismo, no "Ainda é preciso ser cético", de 2000, está nos termos como se faz referência a componentes do problema e do argumento da loucura: "o registro tético do discurso não parece ser mais do que o efeito de um sonho desejoso" (RC 267, ênfase minha). A ocorrência desse "sonho desejoso" é episódica e sua natureza, histórica e contingente — assim como a do ceticismo capaz do retorno à sã vigília. A série de artigos anteriores mostra e confirma essa referência, nas variações que se percebe entre uns e outros. Ao alcançar essa formulação do problema dogmático, que é geral, mas atenta às contingências e particularidades de suas ocorrências; e atenta a seus componentes pensantes (téticos) e sencientes (desejos), Porchat está, enfim, pronto para nos oferecer seu argumento da loucura. Nessa formulação, o argumento é consonante às primeiras inquietaçóes de Porchat, ainda em 1968, e à mais feliz expressão do neopirronismo. Prefiro chamá-lo de tropo ou modo, pois veremos, consiste em ensaio, experimento, exercício, e encontro nele importante contribuição original de Porchat à filosofia. O resultado da experiência

2 Porchat, 1993. Dos I3 artigos de Rumo ao ceticismo, os sete primeiros vêm da coletânea de 1993. 
de leitura desse artigo, compartilhado com as amigas e amigos da homenagem ao Porchat, promovida pelo Professor Roberto Bolzani Filho na Universidade de São Paulo, segue abaixo.

\section{O Argumento da Loucura}

"O Argumento da Loucura" adota, nas palavras de Porchat, um "perfil cartesiano", quer dizer, é escrito em primeira pessoa, em estilo confessional. Algumas explicaçóes para isso, no texto, estão: (i) no descaso com que Descartes trata o argumento, ao citá-lo nas Meditaçóes. Para Porchat, o caso da loucura pode opor obstáculos céticos bem maiores ao dogmatismo do que aqueles imaginados por Descartes, e mesmo por seu primeiro formulador, Carnéades; (ii) na admissão, por Porchat, de ter sido, ele próprio, certa vez, susceptível ao argumento, ao duvidar de sua sanidade mental e se perguntar se, acaso, estaria louco? Nesse perfil, vemos o grande dogmático, Descartes, seguido por Porchat, o investigador cético.

Acompanhando Descartes, espanta a Porchat o fato de, na "Primeira meditação", a que instala o ceticismo, o filósofo náo ter se detido sobre o primeiro argumento que lhe ocorre, que é: "será que estou louco"? Porchat lembra que, para Descartes, as pessoas loucas são aquelas insensatas que têm o cérebro perturbado e ofuscado pelos vapores da bile, que se imaginam reis, quando são muito pobres, que, muito pobres se pensam vestidos de ouro e púrpura, que imaginam que seus corpos são cântaros, ou que seus corpos são feitos de vidro (ênfases minhas). Ele cita a passagem do texto, para, em seguida notar: "E, dito isso, Descartes passa ao argumento do sonho, que ele completa pelo do deus enganador, levando a cabo sua dúvida hiperbólica. A loucura não mais reaparecerá nas Meditaçôes" ( $\mathrm{RC} 324$ ).

Bizarras fantasias à parte, algumas delas perdidas para nós e peculiares ao início da modernidade europeia (os corpos de vidro, por exemplo), ${ }^{3}$ no desvario da loucura, graves erros cognitivos ocorrem: o testemunho dos sentidos se perturba, falsas evidências intelectuais se produzem, o trabalho do próprio entendimento se trava, por vezes, desvirtuando o próprio discurso inferencial. Portanto, as faculdades cognitivas, que vão desde as sensações até o exercício da razão em seus discursos, são prejudicadas ( $\mathrm{RC}_{325}$ ) — em um desenho, digamos mais empirista, ou de continuidade, do conhecimento humano. Noutra passagem, Porchat prefere estabelecer a oposição direta entre loucura e razão, sem se deter, como antes o fizera, no progresso

\footnotetext{
3 A Vinícius França Freitas agradeço e devo uma referência curiosa. Segundo França Freitas: “Thomas Reid chama de 'lunáticos metafísicos' os filósofos que lançam dúvidas sobre a existência dos objetos do mundo externo, comparando-os ao ser humano que acredita que o próprio corpo é feito de vidro". Pergunto: o que terá feito essa crença aparecer e desaparecer? Estará Reid pensando em Descartes ou outros lunáticos?
} 
do conhecimento ( $\mathrm{RC} 332$ ) - agora em um desenho mais estreitamente racionalista do que seria a faculdade capaz de conhecimento verdadeiro ${ }^{4}$.

Mas, enfim, que argumento, é esse, tão ameaçador? O argumento que, contemplado, anula toda e qualquer confiança na razão? Mais ainda, póe em risco a faculdade mesma de pensar de quem o contempla? Diz Porchat:

Um dia ocorreu-me uma dúvida terrível. É que eu me perguntei se era justificada a confiança que eu espontaneamente depositava em minha razão, em minha faculdade de pensar. Refletindo sobre meu próprio empreendimento de investigação filosófica, sobre meus pensamentos e argumentos, pergunteime se deveria realmente confiar na minha capacidade de raciocinar com rigor e de modo seguro, de indagar de modo pertinente e lúcido sobre as questōes que me preocupavam, de bem compreender minhas mesmas dúvidas, assim como as respostas tentativas que para elas tentava formular. Porque, disse-me eu, eu posso estar louco, eu não tenho como excluir a possibilidade de estar louco, eu não tenho como saber que não estou louco. ( $\mathrm{RC} 327$ )

Porchat é contundente: não sei se sou capaz de raciocinar de modo seguro e rigoroso; não sei se sou capaz de indagar pertinente e lucidamente, nem mesmo de compreender minhas dúvidas e as respostas a elas. Posso muito bem-estar louco, e sequer saber disso. Ele diz: não há como eu chegar a uma solução, a uma decisão, a uma resposta que garanta que náo estou louco. Os loucos podem raciocinar rigorosamente e chegar a proposiçóes absurdas; podem partir de falsas premissas e chegar a conclusôes absurdas; podem propor teses que lhes parecem razoáveis; podem até admitir que estáo loucos e mesmo a intersubjetividade, as outras pessoas, podem se garantir umas às outras de sua sanidade, quando são vítimas de loucura coletiva; ou podem ser vítimas de lavagem cerebral.

Em seu ponto inicial, Porchat mantém que a possibilidade da loucura mina qualquer argumento que pretenda demonstrar a sua sanidade, qualquer lampejo de sanidade:

Meu problema era que eu náo conseguia sequer vislumbrar qualquer critério que viesse a propiciar-me uma certeza absoluta de que não estava louco, uma confiança absoluta na sanidade de minha razão. (RC 327)

E

porque não consegui descobrir meio algum de assegurar-me de não estar louco, toda a investigação filosófica em que me engajara pareceu-me irremediavelmente comprometida. ( $\mathrm{RC} 329)$

\footnotetext{
${ }^{4}$ Aqui, isolo breve trecho que é parte de uma questão que Porchat se propóe em RC 332-333, à qual atentarei adiante.
} 
Levado à total paralisia por essa possibilidade, que contamina todo o pensamento, toda a razão (chegando até o senso comum), retirando a confiança em qualquer proposição e argumento que se lhe apresente, Porchat escapa por duas vias céticas. São elas: (i) o argumento da loucura não o pode paralisar porque nenhum argumento é confiável de modo absoluto, nem mesmo ele. Às vezes, o argumento da loucura funciona, porém jamais se estabelece de maneira irremediável. Porchat é movido pelo argumento em alguns momentos, em outros, ele não se impóe forçosamente. Assim, há uma saída. E, (ii) se estivesse louco, como poderia confiar no raciocínio que o levou a essa conclusão? Como poderia confiar na faculdade de que duvida, antes mesmo de exercitá-la? Aqui, a segunda saída, e a possilidade do livre retorno à filosofia.

Aparentemente, temos um argumento e soluçôes simples. Gostaria de examinar um pouco mais esse texto que, devo dizer, exerce grande fascínio sobre mim. Apresento os seguintes apontamentos:

Penso que "O argumento da loucura" passa de um registro filosófico moderno (em que Porchat se identifica com Descartes e seus oponentes), a outro, autobiográfico (em que rememora experiências filosóficas próprias, dolorosas), a um outro ainda, também filosófico, mais geral e atual, em que ele pode, enfim, propor seu original argumento, ou modo, ou tropo da loucura, a se incluir na cultura cética.

Desenvolvendo essa hipótese, vejamos: o argumento da loucura apresenta-se como forte oponente ao dogmatismo de Descartes e, ainda que sumária, a formulação de Porchat, é clara e inteligível. Quando se apresenta num argumento, temos, junto de Porchat, Hume, no ceticismo em relação à razão, do Tratado da natureza humana I.4.I e seção I2 da Investigação sobre o entendimento humano. Mas, quanto tem, o argumento da loucura de Porchat, em comum com esses ancestrais? O que há, nele, de incomum? Sabendo-o filosófico (jamais psiquiátrico), essas são algumas indagaçóes que o artigo suscita, e com as quais esse ensaio vai, agora, se ocupar.

A primeira saída cética de Porchat me parece próxima do "Ceticismo em relação razão" do livro 4 do Tratado da natureza humana de Hume, onde se encontra o seguinte argumento: relaçôes de ideias são raciocínios demonstrativos, pois suas conclusôes não variam com variaçôes na experiência e, como é o caso da álgebra e aritmética, produzem conhecimento. Todavia, tais raciocínios são elaborados por nossas mentes (não em um vácuo), e estas não são infalíveis, podendo cometer erros na cadeia de raciocínios, ao passarem de uma ideia a outra e desta a outra etc, o que faz com que tenhamos que revisá-los, considerando essa possibilidade e, considerando a mesma possibilidade, revisar a revisão, e assim por diante. Por isso, a demonstração decai para probabilidade e, a cada revisão, a probabilidade decai mais um pouco, até se chegar à total extinção da razão. Em primeiro lugar, noto que o ceticismo em relação à razão pode ser tomado como imersão gradual e aterradora no argumento 
da loucura de Porchat. Em segundo lugar, noto que, semelhante a Porchat, Hume, na seção do Tratado, atenta para o fato de que nossa razão não procede num ambiente transmundano - mas mental, finito e falível. A primeira saída de Porchat (a que destitui o argumento da loucura de seu poder absoluto), ainda reminiscente do ceticismo de Hume, diverge, porém, deste, de maneira interessante. Para a seção I.4.I do Tratado, o dogmatismo negativo vence o positivo — se razóes são só o que conta. Não o vence, apenas porque nossa psicologia é constuída de maneira que não suportamos raciocínios táo extensos ao ponto de chegarem ao total extermínio da razão pela diminuição da probablilidade. Somos vencidas pelo cansaço, preguiça, aborrecimento, conformismo, desinteresse etc. Por sua vez, o que seria uma espécie de dogmatismo negativo, sob a forma do argumento da loucura, nada vence, nem venceria. Para Porchat, aqui, não interessa considerar se e quando só razôes contam. A saída do argumento da loucura faz desaparecer a miragem do "espaço aboluto" das puras razóes, como veremos.

A formulação do argumento da loucura de Porchat parece-me próxima também do argumento de Hume, na seção I2, da Investigação sobre o entendimento humano, contra o ceticismo antecedente excessivo de Descartes. Segundo Hume, a dúvida universal sobre nossas faculdades é insuperável, pois não teríamos como avançar além dela, utilizando-nos das mesmas faculdades, das quais desconfiamos. Ou seja, uma vez posta em dúvida nossa faculdade de conhecer, ela torna-se irrecuperável, e o ceticismo, inevitável. Estou ciente da transgressão que cometo ao aproximar o argumento da loucura e dúvida hiperbólica. O próprio Porchat não o faz. Contudo, peço a permissáo e indulgência dos especialistas, alegando que "loucura", nesse argumento, é um termo que recobre vasto território semântico (anteriormente encontramos e, adiante, encontraremos, desatino, insensatez, delírio, maluquice). $\mathrm{Na}$ literatura crítica, decerto, há intérpretes que associam o método da dúvida e a hipótese do gênio maligno a um episódio de paranoia ${ }^{5}$. Concedida a aproximação, vêse que o argumento de Hume, aqui, se assemelha ao da segunda saída de Porchat: pode ser louco o raciocínio que diz ser, ele, o raciocinante, louco, antes de qualquer exercício e evidência? É bem possível que ele se prove, contrariando o argumento, bastante são. Porchat e Hume estão juntos: enquanto este último se dirige à faculdade sob dúvida universal, aquele dirige-se à proposição enunciada quando nesse

\footnotetext{
5 Encontrei, certa vez, uma bela passagem, creio que (mas não garanto) na História do ceticismo de Richard Popkin, associando essa hipótese ao julgamento e condenação das freiras de um convento e seu confessor, numa pequena cidade de Loudun, na França, por pacto e possessão demoníaca. Descartes, ao que parece, acompanhou, de perto, o processo que causou comoção pública e aconteceu alguns anos antes das suas Meditaçóes.
} 
estado. Juntos, também, estão em rejeitar os argumentos da dúvida excessiva antecedente e o argumento da loucura, por se anteciparem à experiência e ao exercício das faculdades suspeitas.

Apesar das semelhanças, o argumento da loucura e suas soluções são irredutíveis aos argumentos de Hume. $\mathrm{O}$ trabalho pode nos parecer próximo do fim, mas não acabou. Finda é a explícita referência a e identificação com Descartes e o pensamento moderno, semi-finda é a experiência rememorada de Porchat, quando viveu o que veio a formular em seu argumento da loucura. Agora, quando nos damos conta de que "loucura" pede mais explicação e, com Porchat, estamos livres para a filosofia, somos instigadas a retomar os componentes do argumento, numa tentativa de, como dizia no início desse ensaio, entendê-los e, espero, entender seu caráter atual, geral e original.

É curioso notar que Porchat, não começa o artigo no primeiro estado. O Porchat de "O Argumento" já é neopirrônico, livre das ilusôes dogmáticas. O Porchat que escreve "O argumento da loucura" viveu, no passado, essas ilusóes — razão porque denomino semi-finda a experiência rememorada. Ele está disposto a revivê-la, tornando o artigo, num sentido, terapêutico, como ele próprio afirma. Isso sugere que ele se dispóe a acompanhar, com simpatia e amiga compaixão, um dogmático afirmativo num experimento terapêutico intelectual de alto risco, pois pode levar ao abandono da filosofia. O desafio é imenso: libertação do "fascínio do absoluto". A "renúncia" ao absoluto é, também, às mais elevadas aspiraçôes de filosofias dogmáticas: intuiçóes infalíveis, inferências seguras, razão objetiva, verdades e certezas definitivas.

Generoso, Porchat acompanha o filósofo do absoluto - rumo ao ceticismo. Quais seriam os experimentos, as experiências conducivas a esse estado, espaço, razão? O que podem significar essas expressôes, em práticas pensantes e filosóficas europeias ocidentais? Como ele proporciona a experiência de uma renúncia ao absoluto? O que significa a "renúncia ao absoluto"?

Porchat ousa: diz serem "loucas" as "filosofias do absoluto", por diversas que sejam. E, com ele, indagamos: o que significa serem loucas? o que significa serem loucas por se pretenderem absolutas? O que significa(m) absoluto(s) na filosofia? A loucura, precisamos reconhecer um sentido próprio, no registro porchatiano, pelo fato de se referir a estados ou transtornos filosofantes, observado em praticantes desta arte, com variado quadro de sintomas. Porchat parece tê-lo tomado de empréstimo da psicologia, psiquiatria, psicanálise. Mas o termo está linguagem comum. Emprega-o, algumas vezes, de forma ligeira, ou, até mesmo, faceira. Quando sua narrativa mais geral está prestes a se iniciar, Porchat recorda seu "irreprimível 
espanto face a certas metafísicas famosas, que [lhe] apareciam esplendidamente delirantes" (RC 329, ênfase minha). Assim como ele, pessoas comuns consideram "bem malucos" os tais filósofos. Mas decerto, o emprego mais consequente do termo está associado à palavra-chave, sabemos, que é "absoluto".

Para melhor acesso a esse "absoluto" no pensamento de Porchat, podemos recuar até "A filosofia e a visão comum do mundo". Nela, o argumento da loucura primeiro se lhe apresentou, diante de projetos e tentativas de criar "espaço próprio e privativo para a filosofia fora do Mundo ... [em] espaço extramundano" — da razáo, alheio à vida comum (RC 59, a última, segundo Porchat, expressão de Danto). Convidadas ao experimento que nos coloca no espaço extramundano, descobrimos que, para nós, é inconcebível. Podemos nos conceber em lugar nenhum, sem deixarmos de ser quem somos? Parece que não. Podemos nos conceber em todos os lugares, de novo, sem deixarmos de ser quem somos? Igualmente, ao que parece, não, impossível. Bastaria lembrar que quem faz o experimento é uma pessoa humana, junto de outras e de ambientes, que pensa e sente com seu corpo, nasce, vive e morre.

Movida pelo argumento, tento trazer à mente experiências particulares, que possam, pelo menos, aludir ao espaço absoluto. De lugar nenhum: para mim, o que mais se aproxima é o breu absoluto de um quarto escuro - causa-me pânico, o coração dispara não favorece a sã filosofia. Um pouco mais distante, mas também solapando o suporte espacial que vem da experiência costumeira, imagino a vertigem. Quando a sofro, perco o chão firme. Assemelha-se ao que poderia ser estar em lugar nenhum, porque náo tenho mais lugar. Mas ela me nauseia, não me deixa pensar, não serve à filosofia. De todos os lugares: vem-me a memória de insuportável hipersensibilidade, após prolongada insônia. Dóia-me, nos olhos, a luz do amanhecer; de volta à casa, perturbava-me, o menor ruído, parecia náo existirem paredes me protegendo deles. O mais suave perfume, tinha odor acre para meu olfato, e os tecidos mais delicados sentiam ásperos na pele. Pergunto: quem pensa bem, sentindo-se tão mal?

Além dessas memórias, o argumento traz-me à lembrança o encantamento que temos ao vislumbramos mundos percebidos por animais náo humanos (ou humanos, de culturas aparentemente distantes das nossas): os olhos facetados de insetos, a identidade geracional de borboletas migratórias, a memória eletromagnética do solo natal, em cada tartaruga marinha, por exemplo. Tantos saberes vibrantes, imersos em particulares, que me trazem à filosofia, e que me parecem contrastar com um espaço extramundano inconcebível que, se fosse concebível, seria, no mínimo, aborrecido em comparação ao mundano. Não o menciono como "espaço extramundano de razôes", pois não vejo com chegarmos a razôes sem experiências. Mais, Porchat, em "O argumento", faz cuidadoso trabalho mostrando que "razóes absolutas" ou certas, objetivas, definitivas, são irrazoáveis, desrazóes, por isso mesmo, loucuras. 
Pior ainda, com seus constrangimentos, tendências dualistas, anseios inatingíveis, angústias, crises, frustraçóes e ilusóes, endurecem o coração e privam-nos de afetos felizes, levam-nos a vidas estéreis, solitárias e deixam a razão, à qual tudo se sacrificou, insatisfeita. O dogmático que passa pelo argumento da loucura e retorna à filosofia, é reconduzido à sua condição humana: seu discurso é precário, sua confiabilidade, relativa, as certezas, provisórias.

Agora, filosofias mundanas, que o argumento da loucura propicia, reconhecemse situadas, circunstanciadas, conversantes, não dualistas. A vida humana não é um progresso, é plena de contingência e acaso. Em nossa conduta, somos ora sensatas, ora insensatas; ora erramos, ora acertamos; ora agraciadas pela boa fortuna, ora atingidas por infortúnios; temos bons e maus encontros; não estamos sós, somos muitas. O mesmo vale para nossas filosofias, mistas, como a vida - nossas razóes sáo sentimentais, nossos sentimentos são pensantes - e, como ela, incertas - princípios não se mantêm indefinidamente, saberes são falíveis. No fim do artigo, Porchat reafirma que "filosofia é em terra firme".

Quando Porchat formulou o argumento da loucura, escolheu a palavra, trazendo-a de campo de alcance conceitual vago, para um sentido filosófico especificamente seu. ${ }^{6}$ A loucura está em filosofias do absoluto e o argumento mostra a impossibilidades dessas filosofias, seu caráter ilusório, quando não pernicioso. $\mathrm{O}$ argumento, como vimos, tem, de fato, dois passos argumentativos, que abrem uma nova cena filosófica. Ele, porém, creio, induz a leitora à experimentação, rememoração, comparaçáo e quem sabe, a tantos outros exercícios que, mais que um argumento, tornam-no um tropo. Irredutível a Carnéades, a Descartes, a qualquer outro pensador, temos aqui - nesse modo do ceticismo - mais uma notável contribuição original de Porchat à filosofia que, assim como as demais, faz lembrar, com saudade, o maravilhoso filosófo, amável, intenso, um gigante, inesquecível mestre ${ }^{7}$.

${ }^{6}$ Quando apresentei esse trabalho, Paulo Faria apresentou objeçôes, as quais agradeço, nas palavras maneira que tento parafrasear a seguir. Diz Faria: "Foucault escreve hiperbolicamente na História da loucura que o que Descartes faz é reiterar e ratificar o gesto de exclusão da loucura pelo qual a razáo moderna se define por oposiçáo ao seu contrário ... qualquer que seja o mérito disso que ele nos conta sobre o processo segundo o qual a loucura se constituiu como doença mental, o que ele diz sobre Descartes é totalmente inaceitável. Porque o que está em jogo é simplesmente a relação entre loucura e argumento. Considerar a hipótese da loucura é minar a pretensão do argumento, seja ele dogmático ou cético, ainda que o propósito seja a suspensão do juízo. Derrida diz que Descartes fez muito bem em não considerar esta hipótese e Porchat fez muito mal [segundo Faria] em considerar com um argumento esta divagaçáo sobre a possibildade de estar louco". Em resposta a Faria, lembro que o texto de Porchat náo reivindica para si mais que um perfil cartesiano, e reafirmo a singularidade de sentido que os termos adquirem em seu argumento, nesse texto.

7 Agradeço imensamente a Roberto Bolzani Filho por promover o encontro na USP em homenagem ao Porchat, que foi ocasiáo de rica convivência filosófica, fortes emoçóes e lembranças, e muita saudade, para mim. Porchat e seu grupo dos céticos, seus alunos e amigos, por pura bondade e pura generosidade, acolheram-me em seus encontros, desde 1995. É indizível a gentileza e ternura desse grupo. Então, a saudade do Porchat é incurável, mas o reencontro com a turma do Porchat é feliz. Tenho sentimentos que Hume talvez chamaria de 'doce 


\section{Referências Bibliográficas}

Descartes, R. (2004) Meditaçóes sobre filosofia primeira. Tradução de Fausto Castilho. Campinas: Editora da Unicamp.

Hume, D. (2000). A Treatise on Human Nature. David Fate Norton e Mary J. Norton (ed.). Oxford: Oxford University Press.

Hume, D. (200I). Tratado da Natureza Humana. Tradução de Deborah Danowski. Sáo Paulo: Editora UNESP - Imprensa Oficial do Estado.

Hume, D. (2004). Investigaçôes sobre o entendimento humano e sobre os princípios da moral. Tradução de José Oscar de Almeida. São Paulo: Editora UNESP — Imprensa Oficial do Estado.

Hume, D. (2010). An Enquiry concerning Human Understanding, Tom Beauchamp (ed.). Oxford: Oxford University Press.

Porchat Pereira, O. (1993). Vida comum e ceticismo. São Paulo: Brasiliense.

Porchat Pereira, O. (2007). Rumo ao ceticismo. São Paulo: Editora Unesp.

melancolia'. Muito obrigada, Roberto e amigos céticos. O ensaio se beneficiou de recursos provenientes de Bolsa de Produtividade em Pesquisa, do Conselho Nacional de Desenvolvimento Científico e Tecnológico (CNPq). 